\title{
Hepatic Steatosis After Neoadjuvant Chemotherapy for Pancreatic Cancer: Incidence and Implications for Outcomes After Pancreatoduodenectomy
}

\author{
K. F. Flick ${ }^{1}$ - M. H. Al-Temimi ${ }^{1}$ - T. K. Maatman ${ }^{1}$ • C. M. Sublette ${ }^{2}$ - J. K. Swensson ${ }^{3}$ - A. Nakeeb ${ }^{1}$ • E. P. Ceppa ${ }^{1}$. \\ T. K. Nguyen ${ }^{1}$ - C. M. Schmidt ${ }^{1}$ - N. J. Zyromski ${ }^{1}$ - M. A. Tann ${ }^{3}$ - M. G. House ${ }^{1}$
}

Received: 24 May 2020 / Accepted: 28 June 2020

(C) 2020 The Society for Surgery of the Alimentary Tract

\begin{abstract}
Background This study aimed to determine the incidence of new onset hepatic steatosis after neoadjuvant chemotherapy for pancreatic cancer and its impact on outcomes after pancreatoduodenectomy.

Methods Retrospective review identified patients who received neoadjuvant chemotherapy for pancreatic adenocarcinoma and underwent pancreatoduodenectomy from 2013 to 2018. Preoperative computed tomography scans were evaluated for the development of hepatic steatosis after neoadjuvant chemotherapy. Hypoattenuation included liver attenuation greater than or equal to 10 Hounsfield units less than tissue density of spleen on noncontrast computed tomography and greater than or equal to 20 Hounsfield units less on contrast-enhanced computed tomography.

Results One hundred forty-nine patients received neoadjuvant chemotherapy for a median of 5 cycles (interquartile range (IQR), 4-6). FOLFIRINOX was the regimen in 78\% of patients. Hepatic steatosis developed in 36 (24\%) patients. The median time from neoadjuvant chemotherapy completion to pancreatoduodenectomy was 40 days (IQR, 29-51). Preoperative biliary stenting was performed in $126(86 \%)$ patients. Neoadjuvant radiotherapy was delivered to $23(15 \%)$ patients. Female gender, obesity, and prolonged exposure to chemotherapy were identified as risk factors for chemotherapy-associated hepatic steatosis. Compared with control patients without neoadjuvant chemotherapy-associated hepatic steatosis, patients developing steatosis had similar rates of postoperative pancreatic fistula ( $8 \%$ (control) vs. $4 \%, p=0.3$ ), delayed gastric emptying $(8 \%$ vs. $14 \%, p=0.4)$, and major morbidity $(11 \%$ vs. $15 \%, p=0.6)$. Ninety-day mortality was similar between groups $(8 \%$ vs. $2 \%, p=0.08)$.

Conclusion Hepatic steatosis developed in $24 \%$ of patients who received neoadjuvant chemotherapy but was not associated with increased morbidity or mortality after pancreatoduodenectomy.
\end{abstract}

Keywords Pancreatic cancer $\cdot$ Neoadjuvant therapy $\cdot$ Hepatic steatosis

\section{Introduction}

Pancreatic cancer is one of the deadliest solid malignancies and represents the third leading cause of cancer-

This paper was scheduled to be presented during an HPB plenary session at the $61^{\text {st }}$ Annual Meeting of the SSAT on May 5, 2020, in Chicago, IL, that was cancelled due to the COVID-19 pandemic.

M. G. House

michouse@iupui.edu

1 Department of Surgery, Indiana University School of Medicine, 545 Barnhill Drive, Emerson Hall 515, Indianapolis, IN 46202, USA

2 Indiana University School of Medicine, Indianapolis, IN, USA

3 Department of Radiology, Indiana University School of Medicine, Indianapolis, IN, USA related deaths in the USA.', 2 Pancreatic ductal adenocarcinoma (PDAC) may present with vague and nonspecific symptoms and is often diagnosed with advanced stage of disease. Although surgical extirpation offers the greatest opportunity for cure, only $10-20 \%$ of patients have resectable disease at the time of diagnosis."

${ }^{4}$ In patients with borderline resectable or locally advanced pancreatic cancer, neoadjuvant chemotherapy (NAC) is recommended to improve patient selection for operative resection. ${ }^{5}{ }^{6}$ Multiagent chemotherapy, including 5-fluorouracil, leucovorin, oxaliplatin, and irinotecan (FOLFIRINOX) or gemcitabine with $n a b$-paclitaxel, offers improvement in overall survival but can have harmful side effects including neurotoxicity and hepatotoxicity such as steatosis or steatohepatitis. ${ }^{71}$ 
The impact of chemotherapy-associated hepatic steatosis on morbidity and mortality after pancreatoduodenectomy (PD) is not well described. Postoperative morbidity in patients undergoing PD remains as high as $40 \%$ despite careful patient selection and experience in perioperative care. ${ }^{12-14}$ While exposure to chemotherapy and chemoradiotherapy does not seem to have a major negative impact on early operative outcomes after PD, direct and indirect effects of neoadjuvant therapy on pancreatectomy-specific outcomes require further investigation. ${ }^{15}-17$

Direct chemotherapy-related effects, including hepatic steatosis, may result in liver injury and impairment of hepatic function and lead to worse surgical outcomes after PD. The purpose of this study was to identify the incidence of hepatic steatosis after neoadjuvant chemotherapy and determine its impact on early postoperative outcomes after pancreatoduodenectomy.

\section{Methods}

\section{Patient Population}

All patients who underwent PD between 2013 and 2018 were prospectively recorded and retrospectively reviewed. Patients receiving NAC for PDAC were included for analysis. Exclusion criteria included patients who did not receive NAC, those with hepatic steatosis indicative of underlying fatty liver disease prior to $\mathrm{NAC}$, and also patients without imaging available for review. Informed consent was obtained for all patients maintained in the pancreatectomy database, and institutional approval was gained through the Indiana University Institutional Review Board.

\section{Definitions and Outcomes}

All monitored American College of Surgeons National Surgical Quality Improvement Program (ACS-NSQIP) variables were evaluated, and the clinical database was augmented through individual patient electronic medical record review. Demographic information included patient age, sex, race, body mass index (BMI), and comorbidities. The type and duration of NAC received, interval between last cycle of NAC and surgery, and preoperative diagnostic imaging were manually reviewed and documented. Preoperative laboratory values were recorded when available within 30 days of the operative date. Other clinical variables of interest included the presence of preoperative obstructive jaundice with or without biliary stenting within 30 days prior to surgery, operative wound classification, use of wound barrier device, duration of operation, pancreatectomy-specific factors, and vascular resection with reconstruction.

Postoperative outcomes included morbidity and mortality, postoperative pancreatic fistula (POPF), delayed gastric emptying (DGE), transfusion requirement, infectious complications, venous thromboembolism, renal insufficiency, major cardiovascular events, percutaneous drain placement, operative re-exploration, length of stay (LOS), nonhome discharge, and 30-day hospital readmission. The International Study Group for Pancreatic Surgery (ISGPS) 2007 and 2016 criteria were used to define DGE and postoperative pancreatic fistula, respectively. ${ }^{18}, 19$ Major morbidity was defined as POPF grade $\mathrm{B}$ or $\mathrm{C}$, DGE grade $\mathrm{B}$, sepsis, or Clavien-Dindo class III or above postoperative complications. ${ }^{20}, 21$ Mortality was recorded as any death within 30 or 90 days of PD.

Preoperative computed tomography (CT) scans before and after NAC were evaluated by a single radiologist for the development of radiographic hepatic steatosis that was defined by relative hypoattenuation of liver parenchyma density compared with spleen. Hypoattenuation was defined as liver attenuation greater than or equal to 10 Hounsfield units (HU) less than that of spleen on noncontrast $\mathrm{CT}$ and greater than or equal to $20 \mathrm{HU}$ less on contrast-enhanced $\mathrm{CT}^{22}$ as is routine practice at our institution. Only patients that developed moderate-tosevere hepatic steatosis were included in the hepatic steatosis patient cohort. Pre- and post-contrast CT imaging may differentiate different degrees of hepatic steatosis, ${ }^{23}$ although standardized attenuation cutoff values for mild, moderate, and severe steatosis are not available. Moderate and severe steatosis was therefore graded qualitatively by the radiologist, ${ }^{24}$ with severe steatosis defined as uniform, marked hypodensity of the liver compared to the spleen. Spleen measurements before and after NAC were objectively measured by the radiologist in its largest craniocaudal axis on the coronal reformats.

\section{Statistics}

Two-way analysis was used to compare preoperative characteristics, intraoperative details, and postoperative outcomes between the subgroups of patients with (study group) or without (control group) NAC-associated hepatic steatosis. Chisquare test was used for categorical variables, and Student's $T$ test was used for continuous variables. Multivariable logistic regression models were used to evaluate the effect of hepatic steatosis on 30-day mortality, overall morbidity, and major morbidity while adjusting for other confounders. A $p$ value of less than 0.05 was considered significant. All analyses were conducted with Stata 11.0 statistical software (College Station, TX). 


\section{Results}

\section{Preoperative Demographics}

A total of 149 patients with PDAC received NAC for a median of 5 cycles (IQR, 4-6 cycles). Ten patients were excluded because of evidence of hepatic steatosis prior to NAC. FOLFIRINOX was the chemotherapy regimen in $78 \%$ of patients, and the next most common NAC combination was gemcitabine plus $n a b$-paclitaxel. Hepatic steatosis developed in $36(24 \%)$ patients after NAC (89\% FOLFIRINOX vs. $11 \%$ gemcitabine $+n a b$-paclitaxel). Patients with hepatic steatosis were significantly more likely to be obese, female, and have more prolonged exposure to chemotherapy, Table 1.

\section{Peri- and Postoperative Outcomes}

The median time from completion of NAC to PD was 40 days (IQR, 29-51 days). The majority (86\%) of patients had preoperative placement of a biliary stent, and radiation therapy was used in less than $20 \%$ of patients. Pancreatic gland texture and objective evidence of portal hypertension, including splenomegaly and thrombocytopenia, at the time of operation were not associated with the development of hepatic steatosis after NAC, Table 1. Perioperative variables were similar between groups except for more frequent use of a wound protector in the cohort of patients who did not develop steatosis, Table 1. On bivariate analysis, major morbidity, overall morbidity, and 30- and 90-day mortality were not statistically different between the hepatic steatosis and nonsteatosis groups. Hospital LOS was nearly 2 days longer in the group without hepatic steatosis, but the remaining postoperative outcomes did not differ between the two groups, Table 2.

Multivariable logistic regression models were performed for major morbidity, overall morbidity, and mortality, Table 3. In patients developing steatosis, no difference was observed in major morbidity, overall morbidity, and mortality after PD compared with patients without NAC-associated hepatic steatosis.

\section{Discussion}

In this series of patients undergoing PD after neoadjuvant chemotherapy, the incidence of neoadjuvant chemotherapyassociated hepatic steatosis was $24 \%$. Identified risk factors for the development of hepatic steatosis in this series included female sex, obesity, and prolonged duration of exposure to NAC. Hepatic steatosis was associated the timeline from last of NAC to PD. Despite the development of radiographically detectable hepatic steatosis, the frequency of postoperative morbidity or mortality was not increased for patients undergoing PD.
The association between steatosis and nonalcoholic steatohepatitis (NASH) on liver histopathology and radiographic hepatic steatosis remains unclear. Furthermore, microscopic changes indicative of liver injury after NAC and the impact on postoperative morbidity and mortality after $\mathrm{PD}$ have not been studied. The impact of hepatic steatosis on postoperative morbidity and mortality has been most thoroughly investigated for patients undergoing hepatic resection for colorectal metastases. Studies have shown mixed results with regard to differences in postoperative morbidity or mortality after liver resection in patients developing hepatic injury from NAC ${ }^{25}-28$ An association between hepatic steatosis and increased infectious complications after hepatic resection may exist. ${ }^{29}$ However, this association was not observed in this current study of patients undergoing PD after NAC exclusively. Several other studies have shown an increase in major postoperative morbidity in patients undergoing hepatectomy with steatohepatitis, ${ }^{30}-32$ but future investigations will need to address the impact of histologically proven NAC-associated hepatic steatohepatitis on pancreatic surgery.

The correlations between hepatotoxicity and duration of NAC and the interval between treatment completion and surgery have been studied previously. Hepatectomy within 4 weeks of NAC completion was associated with increased complications compared with waiting 5-6 weeks. ${ }^{33}$ However, the interval between neoadjuvant therapy and PD for patients with pancreatic cancer did not impact short-term morbidity or mortality. ${ }^{34}$ In the present study, the median interval from NAC to pancreatectomy was 5.7 weeks and was not influenced by the development of NAC-associated hepatic steatosis. Based on these data, this timeline of PD after NAC is assumed to be safe even for patients developing NACassociated hepatic steatosis

FOLFIRINOX, the NAC regimen used most frequently in the present study, is a combination of drugs that includes 5fluorouracil, leucovorin, irinotecan, and oxaliplatin. The underlying mechanisms of drug metabolism and induced hepatotoxicity are poorly understood. A recent meta-analysis found that the nature of injury from NAC is specific to the regimen of agents used. Irinotecan-based therapy tends to cause steatohepatitis, whereas oxaliplatin leads to sinusoidal venular obstruction. "The reversibility of chemotherapyinduced steatohepatitis may require several months.

Although this study found no increase in short-term mortality or morbidity in patients undergoing pancreatectomy with hepatic steatosis, long-term outcomes beyond 30 days will need further investigation. NAC-associated hepatic steatosis may mimic the organ-specific metabolism and histologic changes observed in nonalcoholic fatty liver disease (NAFLD). NAFLD, one manifestation of a metabolic syndrome, may progress to liver fibrosis, cirrhosis, or portal hypertension. ${ }^{37}$,

${ }^{38}$ Thus, chemotherapy-induced hepatic steatosis may result in some degree of portal hypertension and influence vein 
Table 1 Baseline comparison of pre- and perioperative factors

\begin{tabular}{|c|c|c|c|}
\hline & $\begin{array}{l}\text { - Hepatic steatosis } \\
N(\%) \text { or } N(\mathrm{SD})\end{array}$ & $\begin{array}{l}\text { + Hepatic steatosis } \\
N(\%) \text { or } N(\mathrm{SD})\end{array}$ & $P$ value \\
\hline Number of patients & $103(69)$ & $36(31)$ & -- \\
\hline \multicolumn{4}{|l|}{ Preoperative factors } \\
\hline Age $>=70$ (years) & $33(32)$ & $6(17)$ & 0.07 \\
\hline Male sex & $63(61)$ & $11(31)$ & 0.002 \\
\hline Race (white) & $90(87)$ & $33(92)$ & 0.5 \\
\hline $\mathrm{BMI}>=30\left(\mathrm{~kg} / \mathrm{m}^{2}\right)$ & $24(23)$ & $15(42)$ & 0.035 \\
\hline $\mathrm{ASA}>=3$ & $101(98)$ & $36(100)$ & 0.4 \\
\hline Diabetes & $47(46)$ & $10(28)$ & 0.06 \\
\hline Tobacco use & $34(33)$ & $8(22)$ & 0.2 \\
\hline COPD & $5(5)$ & $1(3)$ & 0.6 \\
\hline Dyspnea & $7(7)$ & $3(8)$ & 0.8 \\
\hline Hypertension & $55(53)$ & $19(53)$ & 0.9 \\
\hline Disseminated cancer & $3(3)$ & $1(3)$ & 0.9 \\
\hline Steroid use & $2(2)$ & $0(0)$ & 0.4 \\
\hline$>10 \%$ weight loss & $32(31)$ & $8(22)$ & 0.3 \\
\hline Bleeding disorder & $2(2)$ & $1(3)$ & 0.8 \\
\hline Albumin $>=3(\mathrm{mg} / \mathrm{dL})$ & $90(90)$ & $36(100)$ & 0.049 \\
\hline Platelet count (median, IQR) & $225(177-291)$ & $202(149-253)$ & 0.2 \\
\hline Pneumonia or COPD & $6(6)$ & $1(3)$ & 0.5 \\
\hline Spleen size after NAC (cm) (median, IQR) & $10.9(9.8-12.9)$ & $11.1(9.5-12.9)$ & 0.9 \\
\hline Change in spleen size pre to post NAC (cm) (median, IQR) & $0.5(0-1.1)$ & $0.8(0.2-1.1)$ & 0.4 \\
\hline Obstructive jaundice & $14(14)$ & $1(3)$ & 0.07 \\
\hline Biliary Endostent placement & $87(85)$ & $32(89)$ & 0.5 \\
\hline Radiation & $14(14)$ & $9(25)$ & 0.1 \\
\hline Chronic pancreatitis & $37(36)$ & $12(33)$ & 0.8 \\
\hline Chemotherapy duration (days), median (IQR) & $59(41-79)$ & $75(50-102)$ & 0.009 \\
\hline Chemotherapy (FOLFIRINOX) & $71(74)$ & $32(89)$ & 0.07 \\
\hline Duration from chemotherapy to operation (days), median (IQR) & $40(29-50)$ & $39(29-51)$ & 0.9 \\
\hline \multicolumn{4}{|l|}{ Perioperative factors } \\
\hline Contaminated/dirty wound & $18(18)$ & $4(11)$ & 0.5 \\
\hline Wound barrier device & $102(99)$ & $33(92)$ & 0.023 \\
\hline Pancreatic duct size & & & 0.9 \\
\hline$>6 \mathrm{~mm}$ & $19(20)$ & $7(21)$ & \\
\hline $3-6 \mathrm{~mm}$ & $61(65)$ & $22(65)$ & \\
\hline$<3 \mathrm{~mm}$ & $14(15)$ & $5(15)$ & \\
\hline Gland texture & & & 0.6 \\
\hline Hard & $58(60)$ & $22(65)$ & \\
\hline Intermediate & $17(18)$ & $7(21)$ & \\
\hline Soft & $22(23)$ & $5(15)$ & \\
\hline Pancreatic reconstruction & & & 0.6 \\
\hline Duct to mucosa & $97(94)$ & $33(92)$ & \\
\hline Other & $6(6)$ & $3(8)$ & \\
\hline Vascular resection & $25(24)$ & $13(36)$ & 0.2 \\
\hline Operative duration (minutes) & $303(89.9)$ & $330(93)$ & 0.1 \\
\hline
\end{tabular}

$A S A$ American Society of Anesthesiologists, $B M I$ body mass index, COPD chronic obstructive pulmonary disease, $d L$ deciliter, $I Q R$ interquartile range, $\mathrm{cm}$ centimeter, $\mathrm{kg}$ kilogram, $\mathrm{mg}$ milligram, $\mathrm{mm}$ millimeter, $N A C$ neoadjuvant chemotherapy. Bold indicates significance 
Table 2 Analysis of postoperative outcomes

\begin{tabular}{|c|c|c|c|}
\hline Postoperative outcomes & $\begin{array}{l}\text { - Hepatic } \\
\text { steatosis } \\
N(\%)\end{array}$ & $\begin{array}{l}+ \text { Hepatic } \\
\text { steatosis } \\
N(\%)\end{array}$ & $\begin{array}{l}P \\
\text { value }\end{array}$ \\
\hline Number of patients & 103 & 36 & -- \\
\hline 30-day mortality & $2(2)$ & $3(8)$ & 0.08 \\
\hline 90-day mortality & $2(2)$ & $3(8)$ & 0.08 \\
\hline Major morbidity* & $15(15)$ & $4(11)$ & 0.6 \\
\hline Any morbidity & $30(29)$ & $6(17)$ & 0.1 \\
\hline Pancreatic fistula** & $4(4)$ & $3(8)$ & 0.3 \\
\hline Delayed gastric emptying & $14(14)$ & $3(8)$ & 0.4 \\
\hline Percutaneous drain placement & $3(3)$ & $0(0)$ & 0.3 \\
\hline Transfusion requirement & $24(24)$ & $10(10)$ & 0.6 \\
\hline Hospital LOS (days) & $8.2(4.3)$ & $6.6(2.0)$ & 0.037 \\
\hline Operative return & $0(0)$ & $1(3)$ & 0.09 \\
\hline Nonhome discharge & $15(15)$ & $2(6)$ & 0.2 \\
\hline 30-day readmission & $11(11)$ & $1(3)$ & 0.1 \\
\hline Superficial surgical site infection & $5(5)$ & $0(0)$ & 0.2 \\
\hline Deep surgical site infection & $0(0)$ & $0(0)$ & 1 \\
\hline Organ space infection & $4(4)$ & $1(3)$ & 0.8 \\
\hline Pneumonia & $1(1)$ & $0(0)$ & 0.6 \\
\hline Urinary tract infection & $0(0)$ & $0(0)$ & 1 \\
\hline Unplanned re-intubation & $2(2)$ & $1(3)$ & 0.8 \\
\hline Prolonged intubation ( $>48 \mathrm{~h}$ ) & $1(1)$ & $0(0)$ & 0.6 \\
\hline Pulmonary embolism & $1(1)$ & $0(0)$ & 0.6 \\
\hline Acute renal failure & $0(0)$ & $1(3)$ & 0.09 \\
\hline Cardiac arrest requiring $\mathrm{CPR}$ & $1(1)$ & $1(3)$ & 0.4 \\
\hline Myocardial infarction & $0(0)$ & $1(3)$ & 0.09 \\
\hline Deep venous thrombosis & $4(4)$ & $1(3)$ & 0.8 \\
\hline $\begin{array}{l}\text { Vascular anastomotic thrombosis (patients with vascular } \\
\text { reconstruction) }\end{array}$ & $1(4)$ & $1(7.7)$ & 0.6 \\
\hline Clostridium difficile & $1(1)$ & $0(0)$ & 0.5 \\
\hline Sepsis & $3(3)$ & $0(0)$ & 0.3 \\
\hline
\end{tabular}

$C P R$ cardiopulmonary resuscitation, $L O S$ length of stay, Recon reconstruction

*Included pancreatic fistula grade B or C, delayed gastric emptying (grade B), interventional radiology drain placement, sepsis, unplanned return to the operating room, myocardial infarction, cardiac arrest with CPR, acute renal failure, pulmonary embolism, pneumonia, unplanned re-intubation, organ space infection

**Any grade (including one case of biochemical leak). Bold indicates significance patency rates after portal vein or superior mesenteric vein reconstruction. However, objective measures of portal hypertension, including splenomegaly and hypersplenism, were not found in the patients who developed hepatic steatosis. Furthermore, this study did not reveal a statistically significant difference in vein patency rates for the patient group who developed hepatic steatosis after NAC. Patients who develop fatty liver disease after PD may be at risk for sustained malnutrition that could reduce their tolerance to gemcitabinebased adjuvant chemotherapy. ${ }^{39}$ Hepatic steatosis may contribute toward the high intolerance rate for adjuvant chemotherapy after PD that has been reported in over $30 \%$ of patients.
Aside from the retrospective nature of this study, small sample size is a potential limitation of this study. Negative effects from hepatic steatosis were not observed in this study, but sample size could have reduced the significance of any detectable differences. An additional limitation includes the method of diagnosis of NAC-associated hepatic steatosis. In the present study, CT imaging was used to diagnose this condition, which does not represent a universally accepted standard for diagnosis. ${ }^{41}$ While the standard for diagnosis of hepatotoxicity is invasive liver biopsy, a strength of this study is the uniformity of the noninvasive CT method of diagnosis among all patients. CT assessment provides an alternative, safe preoperative tool that can substitute for invasive liver 
Table 3 Multivariable logistic regression models for mortality, overall morbidity, and major morbidity

\begin{tabular}{llll}
\hline Model for mortality & Odds ratio & $95 \%$ CI & $P$ value \\
Hepatic steatosis & 9.8 & $0.67-141.8$ & 0.09 \\
Age $>$ 70 years & 17.4 & $1.04-289.5$ & $\mathbf{0 . 0 4 7}$ \\
Operative duration* & 1.93 & $1.23-3.02$ & $\mathbf{0 . 0 0 4}$ \\
Disseminated cancer & 114.9 & $0.78-1685$ & 0.06 \\
Model for any morbidity & Odds ratio & $95 \%$ CI & $P$ value \\
Hepatic steatosis & 0.41 & $0.15-1.16$ & 0.09 \\
Operative duration* & 1.14 & $1.002-1.29$ & $\mathbf{0 . 0 4 6}$ \\
Dyspnea & 3.12 & $0.77-12.7$ & 0.1 \\
COPD & 5.61 & $0.92-33.85$ & 0.06 \\
Model for major morbidity** & Odds ratio & $95 \%$ CI & $P$ value \\
Hepatic steatosis & 0.66 & $0.20-2.22$ & 0.5 \\
Operative duration* & 1.13 & $0.97-1.32$ & 0.1 \\
COPD & 3.29 & $0.54-19.7$ & 0.2 \\
\hline
\end{tabular}

$C I$ confidence interval, $C O P D$ chronic obstructive pulmonary disease

*Operative duration in 30-minute intervals

**Included pancreatic fistula grade $\mathrm{B}$ or $\mathrm{C}$, delayed gastric emptying grade $\mathrm{B}$, interventional radiology drain placement, sepsis, unplanned return to the operating room, myocardial infarction, cardiac arrest with cardiopulmonary resuscitation, acute renal failure, pulmonary embolism, pneumonia, unplanned re-intubation, organ space infection. Bold indicates significance

biopsy as a marker of hepatic steatosis in patients under consideration for surgery for pancreatic cancer.

\section{Conclusion}

Limited research has explored the impact of neoadjuvant chemotherapy-associated hepatic steatosis on postoperative outcomes after pancreatectomy. In the present study, hepatic steatosis developed in $24 \%$ of patients who received neoadjuvant chemotherapy. However, hepatic steatosis does not appear to be associated with increased short-term morbidity or mortality after pancreatoduodenectomy.

Author Contribution KF Flick, MH Al-Temimi, TK Maatman, CM Sublette, and JK Swensson were involved in the conception of the project; acquisition, analysis, and interpretation of data; and drafting and revising the work. MG House serves as the mentor and corresponding author for the work and was involved in the conception, interpretation, revision, and final approval of the work; MG House agrees to be accountable for the work. EP Ceppa, A Nakeeb, TK Nguyen, CM Schmidt, NJ Zyromski, and MA Tann were involved in the conception of the project, revision of the work, and final approval.

\section{Compliance with ethical standards}

Informed consent was obtained for all patients maintained in the pancreatectomy database, and institutional approval was gained through the Indiana University Institutional Review Board.
Conflicts of interest The authors declare that they have no conflict of interest.

\section{References}

1. Lennon AM, Wolfgang CL, Canto MI, Klein AP, Herman JM, Goggins $M$ et al. The early detection of pancreatic cancer: what will it take to diagnose and treat curable pancreatic neoplasia? Cancer Res. 2014;74(13):3381-9. doi:https://doi.org/10.1158/ 0008-5472.Can-14-0734.

2. Siegel RL, Miller KD, Jemal A. Cancer Statisticts, 2019. CA Cancer J Clin. 2019;69(January/February ):7-34.

3. Janssen QP, O'Reilly EM, van Eijck CHJ, Groot Koerkamp B. Neoadjuvant Treatment in Patients With Resectable and Borderline Resectable Pancreatic Cancer. Front Oncol. 2020;10: 41. doi:https://doi.org/10.3389/fonc.2020.00041.

4. Strobel O, Neoptolemos J, Jager D, Buchler MW. Optimizing the outcomes of pancreatic cancer surgery. Nat Rev Clin Oncol. 2019;16(1):11-26. doi:https://doi.org/10.1038/s41571-018-0112-1.

5. Tempero MAM, M.P.; Al-Hawary, M. NCCN Clinical Practice Guidelines in Oncology: Pancreatic Adenocarcinoma. NCCN. 2019. https://www.ncen.org/professionals/physician_gls/pdf/ pancreatic_blocks.pdf. Accessed April 14, 20202020.

6. Isaji S, Mizuno S, Windsor JA, Bassi C, Fernandez-Del Castillo C, Hackert $\mathrm{T}$ et al. International consensus on definition and criteria of borderline resectable pancreatic ductal adenocarcinoma 2017. Pancreatology : official journal of the International Association of Pancreatology (IAP) [et al]. 2018;18(1):2-11. doi:https://doi.org/10. 1016/j.pan.2017.11.011.

7. Conroy T, Desseigne F, Ychou M, Bouche O, Guimbaud R, Becouarn $\mathrm{Y}$ et al. FOLFIRINOX versus gemcitabine for metastatic pancreatic cancer. N Engl J Med. 2011;364(19):1817-25. doi: https://doi.org/10.1056/NEJMoa1011923.

8. Goldstein D, El-Maraghi RH, Hammel P, Heinemann V, Kunzmann V, Sastre J et al. nab-Paclitaxel plus gemcitabine for metastatic pancreatic cancer: long-term survival from a phase III trial. J Natl Cancer Inst. 2015;107(2). doi:https://doi.org/10.1093/ jnci/dju413.

9. Suker M, Beumer BR, Sadot E, Marthey L, Faris JE, Mellon EA et al. FOLFIRINOX for locally advanced pancreatic cancer: a systematic review and patient-level meta-analysis. Lancet Oncol. 2016;17(6):801-10. doi:https://doi.org/10.1016/s1470-2045(16) 00172-8.

10. Ramaswamy A, Ostwal V, Pinninti R, Kannan S, Bhargava P, Nashikkar C et al. Gemcitabine-cisplatin versus gemcitabineoxaliplatin doublet chemotherapy in advanced gallbladder cancers: a match pair analysis. Journal of Hepato-Biliary-Pancreatic Sciences. 2017;24(5):262-7. doi:https://doi.org/10.1002/jhbp.439.

11. Robinson SM, Wilson CH, Burt AD, Manas DM, White SA. Chemotherapy-associated liver injury in patients with colorectal liver metastases: a systematic review and meta-analysis. Annals of Surgical Oncology. 2012;19(13):4287-99. doi:https://doi.org/ 10.1245/s10434-012-2438-8.

12. Schmidt CM, Powell ES, Yiannoutsos CT, Howard TJ, Wiebke EA, Wiesenauer CA et al. Pancreaticoduodenectomy: a 20-year experience in 516 patients. Arch Surg. 2004;139(7):718-25; discussion 25-7. doi:https://doi.org/10.1001/archsurg.139.7.718.

13. Cameron JL, He J. Two thousand consecutive pancreaticoduodenectomies. J Am Coll Surg. 2015;220(4):5306. doi:https://doi.org/10.1016/j.jamcollsurg.2014.12.031.

14. Maatman TK, Weber DJ, Timsina LR, Qureshi B, Ceppa EP, Nakeeb A et al. Antibiotic irrigation during pancreatoduodenectomy to prevent infection and pancreatic fistula: 
A randomized controlled clinical trial. Surgery. 2019;166(4):46975. doi:https://doi.org/10.1016/j.surg.2019.05.053.

15. Cools KS, Sanoff HK, Kim HJ, Yeh JJ, Stitzenberg KB. Impact of neoadjuvant therapy on postoperative outcomes after pancreaticoduodenectomy. J Surg Oncol. 2018;118(3):455-62. doi:https://doi.org/10.1002/jso.25183.

16. Verma V, Li J, Lin C. Neoadjuvant Therapy for Pancreatic Cancer: Systematic Review of Postoperative Morbidity, Mortality, and Complications. Am J Clin Oncol. 2016;39(3):302-13. doi:https:// doi.org/10.1097/coc.0000000000000278.

17. Marchegiani G, Andrianello S, Nessi C, Sandini M, Maggino L, Malleo G et al. Neoadjuvant Therapy Versus Upfront Resection for Pancreatic Cancer: The Actual Spectrum and Clinical Burden of Postoperative Complications. Annals of Surgical Oncology. 2018;25(3):626-37. doi:https://doi.org/10.1245/s10434-017-62819.

18. Wente MN, Bassi C, Dervenis C, Fingerhut A, Gouma DJ, Izbicki JR et al. Delayed gastric emptying (DGE) after pancreatic surgery: a suggested definition by the International Study Group of Pancreatic Surgery (ISGPS). Surgery. 2007;142(5):761-8. doi:https://doi.org/ 10.1016/j.surg.2007.05.005.

19. Bassi C, Marchegiani G, Dervenis C, Sarr M, Abu Hilal M, Adham $\mathrm{M}$ et al. The 2016 update of the International Study Group (ISGPS) definition and grading of postoperative pancreatic fistula: 11 Years After. Surgery. 2017;161(3):584-91. doi:https://doi.org/10.1016/j. surg.2016.11.014.

20. Dindo D, Demartines N, Clavien PA. Classification of surgical complications: a new proposal with evaluation in a cohort of 6336 patients and results of a survey. Ann Surg. 2004;240(2): 205-13. doi:https://doi.org/10.1097/01.sla.0000133083.54934.ae.

21. Clavien PA, Barkun J, de Oliveira ML, Vauthey JN, Dindo D, Schulick RD et al. The Clavien-Dindo classification of surgical complications: five-year experience. Ann Surg. 2009;250(2):18796. doi:https://doi.org/10.1097/SLA.0b013e3181b13ca2.

22. Jacobs JE, Birnbaum BA, Shapiro MA, Langlotz CP, Slosman F, Rubesin SE et al. Diagnostic criteria for fatty infiltration of the liver on contrast-enhanced helical CT. AJR American Journal of Roentgenology. 1998;171(3):659-64. doi:https://doi.org/10.2214/ ajr.171.3.9725292.

23. Kim DY, Park SH, Lee SS, Kim HJ, Kim SY, Kim MY et al. Contrast-enhanced computed tomography for the diagnosis of fatty liver: prospective study with same-day biopsy used as the reference standard. European Radiology. 2010;20(2):359-66. doi:https://doi. org/10.1007/s00330-009-1560-x.

24. Idilman IS, Ozdeniz I, Karcaaltincaba M. Hepatic Steatosis: Etiology, Patterns, and Quantification. Semin Ultrasound CT MR. 2016;37(6):501-10. doi:https://doi.org/10.1053/j.sult.2016.08.003.

25. Kooby DA, Fong Y, Suriawinata A, Gonen M, Allen PJ, Klimstra DS et al. Impact of steatosis on perioperative outcome following hepatic resection. J Gastrointest Surg. 2003;7(8):1034-44. doi: https://doi.org/10.1016/j.gassur.2003.09.012.

26. Pawlik TM, Olino K, Gleisner AL, Torbenson M, Schulick R, Choti MA. Preoperative chemotherapy for colorectal liver metastases: impact on hepatic histology and postoperative outcome. J Gastrointest Surg. 2007;11(7):860-8. doi:https://doi.org/10.1007/ s11605-007-0149-4.

27. Pessaux P, Chenard MP, Bachellier P, Jaeck D. Consequences of chemotherapy on resection of colorectal liver metastases. J Visc Surg. 2010;147(4):e193-201. doi:https://doi.org/10.1016/j. jviscsurg.2010.06.004

28. Sahajpal A, Vollmer CM, Jr., Dixon E, Chan EK, Wei A, Cattral MS et al. Chemotherapy for colorectal cancer prior to liver resection for colorectal cancer hepatic metastases does not adversely affect peri-operative outcomes. J Surg Oncol. 2007;95(1):22-7. doi: https://doi.org/10.1002/jso.20632.

29. Kurmann A, Wanner B, Martens F, Klasen J, Stickel F, Montani M et al. Hepatic steatosis is associated with surgical-site infection after hepatic and colorectal surgery. Surgery. 2014;156(1):109-16. doi: https://doi.org/10.1016/j.surg.2014.02.020.

30. Zhao J, van Mierlo KMC, Gomez-Ramirez J, Kim H, Pilgrim CHC, Pessaux $\mathrm{P}$ et al. Systematic review of the influence of chemotherapy-associated liver injury on outcome after partial hepatectomy for colorectal liver metastases. The British journal of surgery. 2017;104(8):990-1002. doi:https://doi.org/10.1002/bjs. 10572 .

31. Behrns KE, Tsiotos GG, DeSouza NF, Krishna MK, Ludwig J, Nagorney DM. Hepatic steatosis as a potential risk factor for major hepatic resection. J Gastrointest Surg. 1998;2(3):292-8. doi:https:// doi.org/10.1016/s1091-255x(98)80025-5.

32. Vauthey JN, Pawlik TM, Ribero D, Wu TT, Zorzi D, Hoff PM et al. Chemotherapy regimen predicts steatohepatitis and an increase in 90-day mortality after surgery for hepatic colorectal metastases. Journal of clinical oncology : official journal of the American Society of Clinical Oncology. 2006;24(13):2065-72. doi:https:// doi.org/10.1200/jco.2005.05.3074.

33. Aloia T, Sebagh M, Plasse M, Karam V, Levi F, Giacchetti S et al. Liver histology and surgical outcomes after preoperative chemotherapy with fluorouracil plus oxaliplatin in colorectal cancer liver metastases. Journal of clinical oncology : official journal of the American Society of Clinical Oncology. 2006;24(31):4983-90. doi:https://doi.org/10.1200/jco.2006.05.8156.

34. Teng A, Nguyen T, Bilchik AJ, O'Connor V, Lee DY. Implications of Prolonged Time to Pancreaticoduodenectomy After Neoadjuvant Chemoradiation. J Surg Res. 2020;245:51-6. doi:https://doi.org/10. 1016/j.jss.2019.07.024.

35. Vigano L, De Rosa G, Toso C, Andres A, Ferrero A, Roth A et al. Reversibility of chemotherapy-related liver injury. J Hepatol. 2017;67(1):84-91. doi:https://doi.org/10.1016/j.jhep.2017.02.031.

36. Meunier L, Larrey D. Chemotherapy-associated steatohepatitis. Ann Hepatol. 2020. doi:https://doi.org/10.1016/j.aohep.2019.11. 012.

37. Hashimoto E, Taniai M, Tokushige K. Characteristics and diagnosis of NAFLD/NASH. J Gastroenterol Hepatol. 2013;28 Suppl 4: 64-70. doi:https://doi.org/10.1111/jgh.12271.

38. Adams LA, Lymp JF, St Sauver J, Sanderson SO, Lindor KD, Feldstein A et al. The natural history of nonalcoholic fatty liver disease: a population-based cohort study. Gastroenterology. 2005;129(1):113-21. doi:https://doi.org/10.1053/j.gastro.2005.04. 014.

39. Okabe H, Yamashita YI, Inoue R, Kinoshita S, Itoyama R, Yusa T et al. Postoperative nonalcoholic fatty liver disease is correlated with malnutrition leading to an unpreferable clinical course for pancreatic cancer patients undergoing pancreaticoduodenectomy. Surg Today. 2020;50(2):193-9. doi:https://doi.org/10.1007/s00595-01901866-x.

40. Xia BT, Habib DA, Dhar VK, Levinsky NC, Kim Y, Hanseman DJ et al. Early Recurrence and Omission of Adjuvant Therapy after Pancreaticoduodenectomy Argue against a Surgery-First Approach. Annals of Surgical Oncology. 2016;23(13):4156-64. doi:https://doi.org/10.1245/s10434-016-5457-z.

41. Cai Z, Yang J, Shu X, Xiong X. Chemotherapy-associated hepatotoxicity in colorectal cancer. J Buon. 2014;19(2):350-6.

Publisher's Note Springer Nature remains neutral with regard to jurisdictional claims in published maps and institutional affiliations. 